Acta Agroph., 2019, 26(2), 29-43

doi: $10.31545 /$ aagr/111981

\title{
MOISTURE DYNAMICS AS RELATED TO CAPILLARY AND DRAINABLE PORES IN THE NILE DELTA SOILS
}

\author{
Abdelmonem Mohamed Ahmed Amer (1) \\ Soil Science Dept., Faculty of Agriculture, Menoufia University, 32511Shebin EI-Kom, Egypt \\ e-mail: amer_abdel@hotmail.com
}

\begin{abstract}
The dynamic of soil moisture may be studied through water flux, storage, moisture conductivity and movement into the soil pore spaces. The volume of pore space in the soil and also the size, shape, type, continuity and distribution of the pores are important characteristics related to the storage, conductivity and movement of water and gases. The movement of water by gravitational forces in the natural soils occurs principally through the non-capillary pores (i.e. rapidly drained pores), while other movements occur in capillaries which may be classified as coarse and fine capillary pores. The unsaturated condition of soil water is a common state in nature after rainfall or as a result of irrigation, therefore, the purpose of this study was to develop equations to describe and estimate the unsaturated hydraulic conductivity $K(\theta)$ in relation to soil pore-size classes that contained the available water in the soil root zone. The equations were based on a water-retention curve, saturated hydraulic conductivity and pore-size function measured from undisturbed cores. The equations were applied to three soil profiles from the Nile Delta and compared with measured $K(\theta)$ data from two field experiments, which were conducted in clay in an unsaturated condition and in sandy soil areas using the internal drainage in situ method. The pore size function $\mathrm{f}(\mathrm{r})$ represents the fraction of the total pore whichvolume, which was contributed by pores with radii from 0 to $\infty$ at the prevailing degree of saturation. Data showed the applicability of the suggested equations for calculating unsaturated hydraulic conductivity in the soil pores even for soils with a high proportion of clay.

Keywords: modelling unsaturated hydraulic conductivity, drainable and capillary pores, alluvial clay and sandy soils
\end{abstract}

\section{INTRODUCTION}

Soil texture and soil structure have a great influence on pore-size distribution, which is a basic consideration when dealing with the problems of soil water management, available water, development of the plant root system, flow and retention of water and heat, and in the investigation of soil strength. Quantifying water flow in soil requires knowledge of hydraulic conductivity $K(\theta)$ and soil water 
retention $h(\theta)$ or $\psi(\theta)$ (Dane and Topp 2002) in the unsaturated condition of soil that is the common state in nature after rainfall or as a result of the irrigation process. Pedotransfer functions ( $P T F$ 's) have been developed to compute $K(\theta)$ and $h(\theta)$ information from soil properties, and numerous techniques exist to calculate K based on $\theta(\mathrm{h}$ ) (Mualem 1976, Kosugi 1999, Poulsen et al. 2002, Schaap and van Genuchten 2006, and Amer et al. 2009). As the pore sizes are the major factors affecting water movement from locations of wet soil to dry ones, the vertical and lateral drainage of water by gravitational forces occurs through large, non-capillary (drainable) soil pores, but redistribution and the upward movement of water occurs through capillary soil pores. Marshal, (1956) specified $\psi=10 \mathrm{kPa}$ as the pressure head corresponding to the boundary between capillary and non-capillary pores. Baver et al. (1972) stated that the soil pore sizes could be classified into non-capillary pores, coarse capillary and fine capillary pores $(F C P)$. The non-capillary pores represented the volume of the large pores or rapidly (quickly) drainable pores $(R D P)$, while coarse capillary pores $(\mathrm{CCP})$ represent the slowly drainable pores $(S D P)$ and water holding pores $(W H P)$.

The objective of this work is to develop equations based on capillary theory for predicting unsaturated hydraulic conductivity $K(\theta)$ and soil moisture flux within the drainable and capillary pores occupied by water and air at different pressure heads which are in turn based on the water retention function $\psi(\theta)$ value in alluvial clay soils.

\section{Theoretical background and Models}

\section{Pore Size Classes}

The relationship between the equivalent cylindrical pore size radius $(r)$ and pressure head ( $h$ in $\mathrm{m}$ ) may be estimated for water filled capillary pores using the following capillary equation (Hillel 1980):

$$
h=\frac{2 \gamma \cos \alpha}{g r\left(\rho_{w}-\rho_{a}\right)}
$$

where: $\gamma$ is the surface tension between liquid and air $\left(\right.$ at $20^{\circ} \mathrm{C}=0.0727 \mathrm{~kg} \mathrm{~s}^{-2}$ ), $\cos \alpha$ is assumed to be 1 for a wettable surface, $g$ is acceleration due to gravity $\left(9.8 \mathrm{~m} \mathrm{~s}^{-2}\right)$, and $\rho$ is the density of water $(w)$ and gas $(a)$. The density of water at $20^{\circ} \mathrm{C}=998 \mathrm{~kg} \mathrm{~m}^{-3}$, much greater than the density of gas, so the density of gas is usually ignored. The pore-size classes were determined from the soil water retention curves (Stakeman 1996) by applying Eq. (1). Of particular interest are the equivalent pressure $(\psi)$ ranges of $0-10,10-33,10-1500,33-1500$, and $>1500 \mathrm{kPa}$, which roughly correspond to rapidly draining pores $(R D P)$, slowly draining pores (SDP), coarse capillary pores $(C C P)$, water-holding pores $(W H P)$ or the available 
water, and fine capillary pores $(F C P)$ respectively. The classes may be combined into $T D P$, total draining pores $(0-33 \mathrm{kPa})$, and $W S P$, total water-storage or capillary pores ( $>33 \mathrm{kPa}$ ). Using Eq. (1), the cutoff equivalent $r$ will be: $14.9,4.46$, and $0.099 \mu \mathrm{m}$ for $\psi$ of 10,33 , and $1500 \mathrm{kPa}$. The following scheme shows the diameters $(\mathrm{d}=2 r)$ of the soil pore sizes in $\mu \mathrm{m}$, whereas diameter $(\mathrm{d} \mu)$ (in $\mu \mathrm{m})$ may be calculated as follows; $\mathrm{d}(\mu)=3 \times 10^{3} \mathrm{~h}^{-1}$ (mbar).

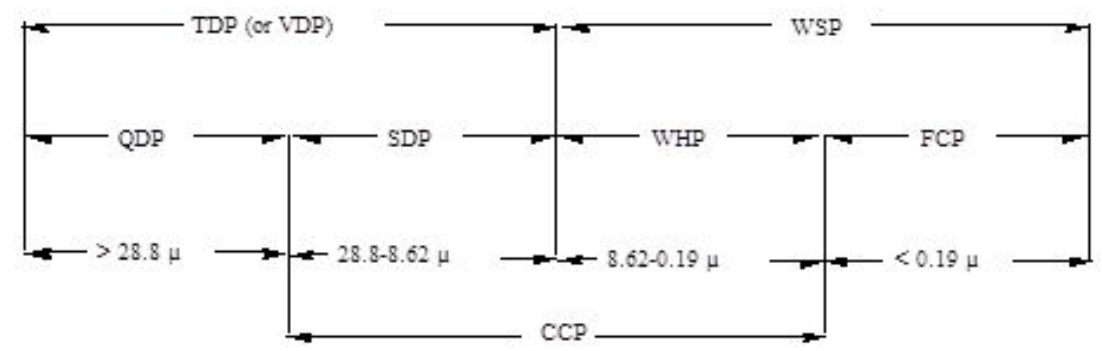

Fig. 1. Pore size diameters and classes

The ratio of air to water in soil or drainable pores to capillary pores $=\left(\theta_{>4.46 \mathrm{\mu m}}\right)$ $/\left(\theta_{<4.46 \mu \mathrm{m}}\right)$ and the $A W R$, available water ratio $=\left(\theta_{0.099-4.46 \mu \mathrm{m}}\right) /\left(\theta_{<4.37 \mu \mathrm{m}}\right)$. The limit to the relationship between adsorbed layers (films) and wetting films is the moisture adsorption capacity ( $W a)$ (Amer 1993), which is considered to be the immobile water content. Amer, $(1982,1993)$ mentioned that the $W a$ is equal to three layers of adsorbed water (films), which may be expressed in the following form:

$$
W a=W m+2 W m e
$$

where: $W m$ is the mono-adsorbed layer of water vapour on soil particles, and $W m e$ is the external mono-adsorbed layer of water vapour. Amer, (2009) used the water vapour adsorption isotherm method with the application of the BET equation to estimate $\mathrm{Wm}$ and $\mathrm{Wme}$.

\section{Hydraulic conductivity (K) in relation to water-filled capillary pores}

The volume of capillaries or capillary-pores in the soil may be expressed as the volume of pores that are occupied with water or with certain moisture intervals $(\Delta \theta \%)$ (Sudnetcyn 1979). At the same height of the capillaries and at unit volume of soil, the number of soil capillaries $(n)$ could be calculated from the following relationship:

$$
n=\frac{\Delta \theta}{100 \pi r^{2}}
$$

where: $\Delta \theta$ is the volume of capillary pores (capillaries) occupied by water (or crosssectional area of the cylindrical capillary pores) and $\pi r^{2}$ is the cross-sectional area (or volume) of one capillary pore. 
The water flow (or discharge Q) through a cylindrical capillary pore may be calculated using Poiseuille's equation:

$$
Q=\frac{\pi r^{4}}{8 \eta} \frac{\Delta \psi}{\Delta L}
$$

where: $\frac{\Delta \psi}{\Delta L}$ is the total hydraulic gradient, $\eta$ is the viscosity $\left(0.1 \mathrm{~kg} \mathrm{~m}^{-1} \mathrm{~s}^{-1}\right.$ at $\left.20^{\circ} \mathrm{C}\right)$, and $\Delta \psi$ is the pressure forces (dyne $\mathrm{cm}^{-2}$ ) acting on distance $\Delta L$ of the moisture interval $(\Delta \theta)$. The hydraulic conductivity of one capillary $(K)$ varies as the fourth power of the capillary radius $(r)$ and is inversely proportional to the viscosity, whereas, $K \propto \frac{\pi r^{4}}{8 \eta}$.

Amer et al (2009), calculated the total $K(\theta)$ for $n$ pores as:

$$
\begin{gathered}
K(\theta)=\sum K=K n=\frac{\pi r^{4}}{8 \eta} \frac{\Delta \theta}{\pi r^{2} 100} \\
K(\theta)=\frac{r^{2} \Delta \theta}{8 \eta 100}\left(\mathrm{~cm}^{3} \mathrm{~s} \mathrm{gm}^{-1}\right)
\end{gathered}
$$

The value of hydraulic conductivity $K(\theta)$ is recognized as being dependent on the nature of the medium and the physical properties of the perfused water $\left(\rho_{\mathrm{w}} g / \eta\right)$, thus:

$$
K(\theta)=\frac{\rho_{w} g r^{2} \Delta \theta}{8 \eta 10^{2}}\left(\mathrm{~cm} \mathrm{~s}^{-1}\right)
$$

The total hydraulic conductivity $K(\theta)$ for $n$ capillaries may be calculated from Eq. (7) in the following form:

$$
K(\theta)=122.5 r^{2} \Delta \theta
$$

It is worth noting that in the directions of $\mathrm{x}, \mathrm{y}$, and $\mathrm{z}$ among long tortuous pathways of different pore sizes, the $K(\theta)$ value varies by orders of magnitude due to very small changes in soil porosity and in water potential as well as in the degree of saturation $\left(\theta_{i} / \theta_{s}\right)$. Then $K(\theta)$ values for any pore-size class will be reduced by 200-fold (Sudnetcyn 1979 and Amer 2001) under certain conditions, particularly in clay soils, at certain water content values $\left(\theta_{i}\right)$ Eq. (7) becomes;

$$
K(\theta)=\frac{\rho_{w} g r^{2}}{8 \eta T} \frac{\Delta \theta_{i}}{100}
$$

where: $T=$ tortuous pathways factor $(T=200)$ of capillary pores and $\Delta \theta_{i}$ is the soil moisture content in a certain pore-size class $(i)$.

However, a matching factor $C=\frac{K_{S}}{K_{C}}$ must be added to Eq. $(7,8)$ and Eq. (9) to predict the unsaturated hydraulic conductivity $K(\theta)$, as follows:

$$
K(\theta)=\frac{K_{S}}{K_{C}} \frac{\rho_{w} g r^{2} \Delta \theta}{8 \times 10^{2} \eta T}
$$


where: $K_{s}$ is the hydraulic conductivity measured during saturation conditions, $K_{c}$ is the hydraulic conductivity calculated at water content $(\Delta \theta)$ close to $\psi=1 \mathrm{kPa}$ and pore radius $\mathrm{r}=0.015 \mathrm{~cm}$ i.e.:

$$
K_{C}=K(\theta)=122.5(0.012)^{2} \Delta \theta_{R D P}
$$

By applying the pressure forces $\Delta \psi$ in relation to the head (h, $\mathrm{cm}$ ) (Sudnetcyn 1979) and substituting with Eq. (1), Eq (5) would be as follows:

$$
\begin{gathered}
K(\theta)=\sum K=K n \propto \frac{5 \times 10^{8} \pi}{8 \eta \psi^{4}} \frac{\Delta \theta \psi^{2}}{2.25 \times 10^{6} \pi} \\
K(\theta)=\frac{224 \Delta \theta}{8 \eta \psi^{2}}=\frac{2.8 \times 10^{3} \Delta \theta}{\psi^{2}}\left(\mathrm{~cm}^{3} \mathrm{~s} \mathrm{gm}^{-1}\right) \\
K(\theta)=\frac{28 \rho_{w} g \Delta \theta}{\eta \psi^{2}}=\frac{2.8 \times 10^{3} \rho_{w} g \Delta \theta}{\psi^{2}}\left(\mathrm{~cm} \mathrm{~s}^{-1}\right) \\
K(\theta)=2.75 \times 10^{6} \frac{\Delta \theta}{\psi^{2}}
\end{gathered}
$$

Eqns. (14) and (15) indicate the possibility of applying the soil moisture characteristics curve $[\psi(\Delta \theta)$ function] in order to predict $K(\theta)$.

From Eq. $(7,8)$ and $(10)$, the calculation of $K(\theta), \mathrm{cm} \mathrm{s}^{-1}$ in different pore classes (FCP, WHP, SDP and RDP) may be simplified as follows:

$$
\begin{gathered}
K(\theta)_{F C P}=122.5\left(0.10 \times 10^{-4}\right)^{2}\left([\Delta \theta]_{F C P}-W a\right) \frac{K_{S}}{K_{C}} \\
K(\theta)_{W H P}=K(\theta)_{F C P}+122.5\left(4.21 \times 10^{-4}\right)^{2} \frac{K_{S}}{K_{C}}[\Delta \theta]_{W H P} \\
K(\theta)_{S D P}=K(\theta)_{W H P}+122.5\left(10.09 \times 10^{-4}\right)^{2} \frac{K_{S}}{K_{C}}[\Delta \theta]_{S D P} \\
K(\theta)_{R D P}=K(\theta)_{S D P}+\frac{K(\theta)_{S D P}+K_{S}(\text { measured })}{2}\left(\mathrm{~cm} \mathrm{~s}^{-1}\right)
\end{gathered}
$$

At a series of soil moisture retention levels, the $[\Delta \theta]_{F C P,}[\Delta \theta]_{W H P},[\Delta \theta]_{S D P}$, and $[\Delta \theta]_{\mathrm{RDP}}$ are represented by the volumetric water content $\%$ of fine capillary pores $F C P$, water-holding pores $W H P$, slowly drainable pores $S D P$, and rapidly drainable pores $R D P$, respectively (with radii $r, \mathrm{~cm}$ ), and $W a$ is adsorbed water capacity $\%$. The radius $(r)$ of the $R D P$ category of pores in the assumed to be the largest for the class because the data was cumulated starting at the dry location and the largest radius of the smaller class is the lower boundary for the next larger class. This means that the $K(\theta)$ value is obtained in a cumulative way, and all pores, which still contain water contribute to the conductivity obtained. Therefore, they also include the contribution of the pore classes, which have smaller size. The $K$ cutoff $r$ 
was matched with the $\Delta \theta$ class, as given in Table 2. The $W a$ value was subtracted from $\Delta \theta$ of the $>1500 \mathrm{kPa}$ class. The larger classes included the $K$ values from the smaller classes.

\section{Water drainage rate as related to soil pore size}

Water flow is directed from locations of high hydraulic pressure to those of low hydraulic pressure head in the soil. The rate of water movement from the wetted zone, low tension locations towards dry, high tension ones is dictated by pore size. Water must continually move through a greater distance to reach the dry zone, also, as the moisture content of the wetted zone decreases through the loss of water, the rate of water conduction is also reduced (Khater 1978). This rate may be predicted by applying the hydraulic gradient in Eq. 4 expressed in terms of pressure head (cm), where, $\Delta \psi=\rho_{w} g \Delta h$, the discharge (Q) of one capillary may be rewritten as:

$$
Q=\rho_{w} g \frac{\pi r^{4}}{8 \eta} \frac{\Delta h}{\Delta L}\left(\mathrm{~cm}^{3} \mathrm{~s}^{-1}\right)
$$

where: $\Delta h / \Delta L$ is the hydraulic gradient (matric + gravitational), and $\Delta \mathrm{h}$ is the pressure head range acting on the $\Delta L$ range or the change in distance for the $\theta$ range.

By comparing Eq.7 and Eq.20 one obtains the water flow (total discharge) or water drainage rate $(q)$ in $L^{3} T^{-1}$ for $n$ capillaries as expressed by the following equation:

$$
q=\frac{10^{2} \pi r^{2}}{\Delta \theta} K(\theta) \frac{\Delta h}{\Delta L} \quad\left(\mathrm{~cm}^{3} \mathrm{~s}^{-1}\right)
$$

where: the gradient, $\Delta h / \Delta L$ may be set at approximately 1 , and for the cross section area, $\pi r^{2}$ was based on the largest $r$ of the class.

\section{MATERIALS AND METHODS}

\section{Soil sampling and analyses}

Three alluvial soil profiles which differed in their clay content $\%$ and salinity were chosen for the study. The first (I) and second (II) profiles are non-saline clay soils having $40-45$ and $56-63 \%$ of clay content respectively. The first profile was taken from the farm of the Faculty of Agriculture, Shebin El-Kom, and the second from Epshan, Kafr El-Sheikh. The third profile (III) represents a saline clay soil was taken from El-Khamsein, Kafr El-Sheikh, with $63-74 \%$ clay. Soil samples were taken at various depths: 0-30, 30-60, and $60-90 \mathrm{~cm}$ for each profile. Undisturbed soil samples were collected in steel cylinders $150 \mathrm{~mm}$ long and with a $60 \mathrm{~mm}$ inner diameter. The undisturbed soil samples were used to determine bulk density, the soil water retention curve was determined through desorption for pressure heads of up to $100 \mathrm{kPa}$, and the saturated hydraulic conductivity value was calculated based on the falling head method (Klute 1972). For all sites, the disturbed samples were 
air-dried, gently crushed, sieved through a $2 \mathrm{~mm}$ sieve, and used for the analysis of desorption at higher pressure heads, salinity $(E C)$, and sodium adsorption ratios $(S A R)$. The standard physical and chemical analyses of the studied soils are presented in Table (1) (according to Sparks et al. 1996, Dane and Topp 2002).

\section{Field experiments and $K(\theta)$ measurement}

In order to test the applicability of the assumed equations for predicting unsaturated hydraulic conductivity $K(\theta)$, two field experiments were conducted for the measurement of $\mathrm{K}$ in unsaturated conditions using the internal drainage in situ method which was introduced by Hillel (1980). In order to apply this method, experimental research was undertaken in situ using clay soil [IV] and for sandy soil $[\mathrm{V}]$ areas as follows:

\section{Determination of $K(\theta)$ in clay soil [IV]}

A plot with the dimensions of $6 \mathrm{~m} \times 6 \mathrm{~m}$ (or $36 \mathrm{~m}^{2}$ ) with no plants was chosen as the location of the first soil profile (Shebin El-Kom). The devices for conducting the measurements were located in the middle of it in order for the processes and the measurements to remain unaffected by the boundaries. Four tensiometers were installed within the test site and a digital electronic device for soil water content measurement was placed close to each tensiometer. The electronic devices were calibrated before use. Water was then ponded on the surface and the plot was irrigated for long enough so that the entire profile became as wet as possible. After that, the soil was covered by a sheet of plastic so as to prevent any water flow across the surface.

Table 1. Physical and chemical properties of the studied soils.

\begin{tabular}{|c|c|c|c|c|c|c|c|c|c|c|c|}
\hline \multirow{2}{*}{$\begin{array}{l}\text { Soil profile } \\
\text { and location }\end{array}$} & \multirow{2}{*}{$\begin{array}{l}\text { Soil } \\
\text { depth } \\
(\mathrm{cm})\end{array}$} & \multirow{2}{*}{$\begin{array}{c}E C^{*} \\
\mathrm{dS} \mathrm{m} \mathrm{m}^{-1}\end{array}$} & \multirow{2}{*}{$S A R$} & \multirow{2}{*}{$\begin{array}{c}\rho_{\mathrm{b}} \\
\text { g.cm } \mathrm{cm}^{-3}\end{array}$} & \multirow{2}{*}{$\begin{array}{c}\mathrm{CaCO}_{3} \\
\%\end{array}$} & \multicolumn{3}{|c|}{$\begin{array}{c}\text { Particle size } \\
\text { distribution \% }\end{array}$} & \multirow{2}{*}{$\begin{array}{l}\text { Texture } \\
\text { class }\end{array}$} & \multirow{2}{*}{$\begin{array}{c}\theta_{s} \\
\mathrm{~m}^{3} \mathrm{~m}^{-3}\end{array}$} & \multirow{2}{*}{$\begin{array}{c}K_{s} \\
\mathrm{~cm} / \mathrm{h}\end{array}$} \\
\hline & & & & & & Sand & Silt & Clay & & & \\
\hline I & $0-30$ & 1.90 & 3.79 & 1.30 & 2.10 & 24.56 & 35.68 & 39.76 & clay loam & 0.6577 & 10.70 \\
\hline She & $30-60$ & 1.60 & 4.73 & 1.38 & 1.84 & 23.60 & 34.75 & 41.65 & clay & 0.6931 & 9.96 \\
\hline El-Kom & $60-90$ & 2.00 & 9.90 & 1.35 & 0.92 & 22.29 & 32.91 & 44.80 & clay & 0.6628 & 7.82 \\
\hline \multirow{3}{*}{$\begin{array}{l}\text { II } \\
\text { Ebshan }\end{array}$} & $0-30$ & 2.30 & 6.48 & 1.27 & 0.84 & 21.98 & 15.37 & 62.65 & clay & 0.7212 & 5.65 \\
\hline & $30-60$ & 1.89 & 4.75 & 1.28 & 0.98 & 14.31 & 18.69 & 67.00 & clay & 0.7684 & 4.14 \\
\hline & $60-90$ & 1.22 & 3.11 & 1.28 & 0.79 & 16.44 & 24.38 & 59.18 & clay & 0.7325 & 4.25 \\
\hline \multirow{3}{*}{$\begin{array}{l}\text { III } \\
\text { El-Khamsin }\end{array}$} & $0-30$ & 6.00 & 12.93 & 1.21 & 0.67 & 8.26 & 28.50 & 63.24 & clay & 0.7436 & 3.86 \\
\hline & $30-60$ & 6.44 & 16.05 & 1.19 & 0.82 & 7.38 & 23.62 & 69.00 & clay & 0.7828 & 2.49 \\
\hline & $60-90$ & 8.12 & 17.83 & 1.18 & 0.56 & 9.04 & 20.46 & 70.50 & clay & 0.7540 & 2.32 \\
\hline
\end{tabular}

* $E C$ is electrical conductivity, $\rho \mathrm{b}$ is bulk density, $\theta$ s is water content saturation, $K s$ is saturated hydraulic conductivity, $S A R=\frac{N a^{+}}{\sqrt{\frac{C a^{++}+M g^{++}}{2}}}$. 
As the internal drainage was proceeding, the measurements of both soil water potential, $\psi$ (soil water suction) and soil water content $(\theta)$ were made simultaneously throughout the soil profile up to a depth of $60 \mathrm{~cm}$. The variation in both the volumetric wetness and matric suction with time for each depth were functioned in a draining profile. Thus, the required dependencies and functions were used for $K(\theta)$ estimation. The measurements were performed 10 times. The period between the sequent measurements was kept constant at three days, which means that the entire period of the experiment was approximately 30 days.

\section{Determination of $K(\theta)$ in sandy soil [V]}

The experiment was conducted in Inshas sandy soil (located at eastern Nile Delta) using a neutron scattering meter for detecting the volumetric soil moisture $(\theta)$ content at $45 \mathrm{~cm}$ and $60 \mathrm{~cm}$ depths. The average soil moisture content depletion at depths of $0-45 \mathrm{~cm}$ and $0-60 \mathrm{~cm}$ were determined with time $(t, \mathrm{hr})$ from the beginning of the irrigation process to the end of the experiment after 192 hours. The depletion rate $[d \theta / d t]$ is used to determine the soil moisture fluxes $[L d \theta / d t]$ at $L=45$ and $60 \mathrm{~cm}$ depth. The hydraulic gradient $[\mathrm{dH} / \mathrm{dZ}]$ values may be estimated around each soil depth using tensiometers. Hence, the unsaturated hydraulic conductivity $K(\theta)$ may be determined at a certain soil depth $(\underline{L})$ using the following equation (Hillel 1980):

$$
K(\theta)_{L}=\frac{L\left(\frac{d \theta}{d t}\right)}{\left(\frac{d H}{d Z}\right)_{L}}
$$

\section{RESULTS AND DISCUSSION}

\section{Pore Size Distribution of the studied soils}

The volume of the pore space size and the continuity of pores through different soils are not constant but vary according to changes in the physical and chemical conditions of the soil (Vomocil 1965). Table 2 and Table 3 show the pore size distribution as a percentage of the total bulk volume of the soil, and as a percentage of the total pore space $(T V P)$, i.e. $T V P=R D P+S D P+W H P+F C P=100 \%$.

The result data indicated that the volume of the total drained pores $(T D P)$ and consequently the air pores as well as the air/water ratio reached a maximum value at a subsurface depth of $(30-60 \mathrm{~cm})$ for the soil profile No. I (Shebin El-Kom), wheras they reached a maximum value at the surface depth of $(0-30 \mathrm{~cm})$ for soil profiles II (Epshan) and III (El-Khamsein). This means that the water storage value \% WSP represented as $W H P \%+F C P \%$ was at a minimum in the depths mentioned above and was more pronounced at a depth of 0-30 $\mathrm{cm}$ for profile I and at a depth of 30-60 
$\mathrm{cm}$ for profiles II and III. However, the values of water storage were different at the depth of the profiles according to the distribution of the pore system within the soil profiles.

Table 2. Pore size classes as a percentage of the total bulk volume in the studied soils

\begin{tabular}{|c|c|c|c|c|c|c|c|c|c|}
\hline $\begin{array}{l}\text { Soil profile } \\
\text { and location }\end{array}$ & $\begin{array}{l}\text { Soil } \\
\text { depth } \\
(\mathrm{cm})\end{array}$ & $\begin{array}{c}R D P \\
<10 \mathrm{kPa} \\
(\Delta \theta)\end{array}$ & $\begin{array}{c}S D P \\
10-33 \mathrm{kPa} \\
(\Delta \theta)\end{array}$ & $\begin{array}{c}T D P \\
<33 \mathrm{kPa} \\
(\Delta \theta)\end{array}$ & $\begin{array}{c}W H P \\
33-1500 \\
(\Delta \theta)\end{array}$ & $\begin{array}{c}C C P \\
10-1500 \\
(\Delta \theta)\end{array}$ & $\begin{array}{c}F C P \\
>1500 \\
(\Delta \theta)\end{array}$ & $\begin{array}{c}\text { WSP } \\
>33 \mathrm{kPa} \\
(\Delta \theta)\end{array}$ & $W a \% *$ \\
\hline & $0-30$ & 1.25 & 8.10 & 9.35 & 31.68 & 39.78 & 24.74 & 56.42 & 11.08 \\
\hline \multirow{4}{*}{$\begin{array}{l}\text { Shebin } \\
\text { El-Kom }\end{array}$} & & 1.33 & 16.30 & 17.63 & U & 45.20 & 22.78 & 1.68 & \\
\hline & 6 & 2.00 & 1 & 15.28 & 29.54 & 42.82 & 21.46 & 00 & \\
\hline & $\mathrm{n}$ & 1.53 & 1 & 14.09 & 04 & 42.60 & 22.99 & 53.03 & \\
\hline & & 3 & 20 & & 22.85 & 37.85 & 25.39 & 18.24 & 12.31 \\
\hline 11 & 3 & 18 & 1 & 3 & 0 & 50.75 & 22.91 & 9.01 & \\
\hline \multirow[t]{3}{*}{ Ebshan } & & & & & & 54 & 65 & 97 & \\
\hline & & & & & & 47 & & 41 & \\
\hline & & & & & & 49.40 & 22.76 & 55.24 & \\
\hline III & $30-60$ & 1.41 & 13.71 & 15.12 & 39.36 & 53.07 & 23.80 & 63.16 & 14.67 \\
\hline \multirow{2}{*}{ El-Khamsen } & & & & & & & & & \\
\hline & 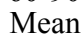 & 1.86 & 15.01 & 16.87 & 36.12 & 51.13 & 22.51 & 58.63 & 14.32 \\
\hline
\end{tabular}

* Wa - water adsorption capacity

Table 3. Pore size classes as a percentage of the total volume of pores of the investigated soils

\begin{tabular}{|c|c|c|c|c|c|c|c|c|c|}
\hline $\begin{array}{l}\text { Soil profile } \\
\text { and location }\end{array}$ & $\begin{array}{l}\text { Soil } \\
\text { depth }\end{array}$ & $\begin{array}{c}R D P \\
<10 \mathrm{kPa}\end{array}$ & $\begin{array}{c}S D P \\
10-33 \mathrm{kPa}\end{array}$ & $\begin{array}{c}W H P \\
33-1500 \mathrm{kPa}\end{array}$ & $\begin{array}{c}F C P \\
>1500 \mathrm{kPa}\end{array}$ & $\begin{array}{c}\quad T D P \\
<33 \mathrm{kPa}\end{array}$ & $\begin{aligned} & W S P \\
> & 33 \mathrm{kPa}\end{aligned}$ & AWR * & $\begin{array}{c}\text { Air/Water } \\
\text { ratio }\end{array}$ \\
\hline & $(\mathrm{cm})$ & $\Delta \mathrm{S} \%$ & $\Delta S \%$ & $\Delta \mathrm{S} \%$ & $\Delta \mathrm{S} \%$ & $\Delta \mathrm{S} \%$ & $\Delta \mathrm{S} \%$ & & \\
\hline I & $0-30$ & 1.90 & 12.32 & 48.16 & 37.62 & 14.22 & 85.78 & 0.56 & 0.17 \\
\hline Shebin & $30-60$ & 1.92 & 23.52 & 41.70 & 32.87 & 25.44 & 74.57 & 0.56 & 0.34 \\
\hline \multirow{2}{*}{ El-Kom } & $60-90$ & 3.02 & 20.04 & 44.56 & 32.38 & 23.06 & 76.94 & 0.58 & 0.30 \\
\hline & Mean & 2.28 & 18.63 & 44.81 & 34.29 & 20.91 & 79.10 & 0.57 & 0.27 \\
\hline II & $0-30$ & 5.47 & 27.70 & 31.65 & 35.17 & 33.17 & 66.82 & 0.47 & 0.49 \\
\hline \multirow[t]{2}{*}{ Ebshan } & $\begin{array}{l}30-60 \\
60-90\end{array}$ & $\begin{array}{l}4.14 \\
308\end{array}$ & $\begin{array}{l}19.06 \\
2199\end{array}$ & 46.98 & 29.82 & 23.20 & $\begin{array}{l}76.79 \\
74.93\end{array}$ & 0.61 & 0.30 \\
\hline & Mean & 4.23 & 22.92 & 42.02 & 30.83 & 27.15 & 72.85 & 0.58 & 0.37 \\
\hline III & $0-30$ & 2.96 & 22.75 & 43.68 & 30.61 & 25.71 & 74.29 & 0.59 & 0.35 \\
\hline \multirow{3}{*}{ El-Khamsen } & $30-60$ & 1.80 & 17.51 & 50.28 & 30.40 & 19.31 & 80.68 & 0.62 & 0.24 \\
\hline & $60-90$ & 2.65 & 19.50 & 49.44 & 28.41 & 22.15 & 77.85 & 0.64 & 0.28 \\
\hline & Mean & 2.47 & 19.92 & 47.80 & 29.81 & 22.39 & 77.61 & 0.62 & 0.29 \\
\hline
\end{tabular}

* AWR is available water ratio, and $\Delta \mathrm{S}$ is saturation degree

At depths of $0-30 \mathrm{~cm}$ and $60-90 \mathrm{~cm}$ it was obvious that the slowly drained pores $(S D P)$ as well as the fine capillary pores $(F C P)$ were more prevalent in profile II than in the other two profiles. This may be due to the high clay content in the relevant profile when compared with profile I, and to the low salinity and $S A R$ when compared with profile III. However, the $S D P$ and $F C P$ values were higher at a depth of $30-60 \mathrm{~cm}$ at profile I and profile III respectively. 
It should be noted that, in the same profile, the fine capillary pores were increasing in concentration in the surface layers to a greater extent than they were in the subsurface ones (except profile III). The relatively higher values of $F C P$ in the surface layers may be due to cultivation practices (El-Sharkawy 1994). On the other hand, coarse capillary pores $(C C P)$ were more prevalent in the subsurface depth $(30-60 \mathrm{~cm})$ in all studied soils. The values were more enhanced in the saline clay soil (profile III) than in the other two profiles. The distribution of water holding pores $(W H P)$ were different according to the depths of all the soil profiles under investigation. However, the mean values of $C C P$ and $W H P$ had the following distribution: profile III $>$ profile II $>$ profile I (Table 2). These results are in agreement with those obtained by Hanna et al. (1997) and were due to the fact that alluvial clay soils (profiles II and III) expand considerably when moistened as do most alluvial soils in the Nile Delta. Moreover, the data in Tables (2 and 3) showed that the values of $W H P$ were greater than those of $R D P, S D P$ and $F C P$ in all studied soil profiles. Therefore, it may be concluded that the distribution of different pores in these soil profiles are as follows: $W H P>F C P>S D P>R D P$.

With regard to the relationship between water suction $(\psi)$ and pore size distribution, the $h(\theta)$ function of the investigated soils indicated that the water is drained entirely from $R D P$ at suction values of approximately $10 \mathrm{kPa}$, and from $S D P$ when the suction values ranged between $10^{1.5}-10^{1.8} \mathrm{kPa}$ for the three soil profiles. Also, suction values of $10^{3.2} \mathrm{kPa}$ and $1.58 \times 10^{5} \mathrm{kPa}$ correspond to $W H P$ and $F C P$ respectively, while $10^{6} \mathrm{kPa}$ is the maximum suction value that could be found in soils with the finest pores. These results correspond to those found by El-Sharkawy (1994).

\section{$K$ models as applied at capillary and drainable pores}

In numerical terms the saturated hydraulic conductivity $\left(K_{s}\right)$ value was low for the saline clay soil at El-Khamsen, but variability was very highly probable (Table 1). This is consistent with the results of Khan and Afzal (1989) who showed that the $K$ value was positively correlated with pores with suction values of 1 to $33 \mathrm{kPa}$, and was adversely affected by high electrical conductivity and $S A R$.

The data presented in Table 4 and illustrated in Fig. 2 show the values of unsaturated hydraulic conductivity $K(\theta)$ as calculated by the assumed models, 7-10 for different soil pore size classes for clay saline and non-saline soil profiles. It is clear that the values of unsaturated hydraulic conductivity $K(\theta)$ at $F C P$ are very low, since the values fluctuated between $2.12 \times 10^{-9}$ to $1.01 \times 10^{-8} \mathrm{~cm} \mathrm{~s}^{-1}$ in the studied soil profiles I and III. Nevertheless, they were higher in the surface depth $(0-30 \mathrm{~cm})$ than in the subsurface $(30-60 \mathrm{~cm})$ one for both profiles I and III. This may be due to the difference of adsorption water capacity ( $\mathrm{Wa} \%$ ) in the two soil profiles (Amer 1993). The $K(\theta)$ values of WHP were higher in the surface layer $(0-30 \mathrm{~cm})$ than in the subsurface one $(30-60 \mathrm{~cm})$ in clay soil profile I (Shebin El-Kom), while an alternative trend was observed in the 
saline-clay soil profile III (El-Khamsein). The mean values were $5.335 \times 10^{-5} \mathrm{~cm} \mathrm{~s}^{-1}$ for profile I and $1.385 \times 10^{-5}$ for profile III. In general, the $K(\theta)$ values at $W H P, S D P$ and $R D P$ - as well as the saturated hydraulic conductivity $\left(K_{S}\right)$ - were less in the saline clay soil profile (III) than in the clay soil profile (I). This is due to the high clay content and to the effect of the relatively high salinity ${ }_{K} S_{S}$ nd $S A R$ in profile III (Fig. R. $_{3}$.

Table 4. Unsaturated hydraulic conductivity $K\left(\overline{K^{\prime}}\right)$ of the studied $\overline{K_{K}}$ sils for various pore size classes as calculated by the proposed models

\begin{tabular}{|c|c|c|c|c|c|c|c|c|c|c|c|}
\hline \multirow{2}{*}{$\begin{array}{c}\text { Soil } \\
\text { profile } \\
\text { and } \\
\text { location }\end{array}$} & \multirow{2}{*}{$\begin{array}{c}\text { Soil } \\
\text { depth } \\
\text { (cm) }\end{array}$} & \multicolumn{2}{|c|}{$R D P,<10 \mathrm{kPa}$} & \multicolumn{2}{|c|}{$S D P, 10-33 \mathrm{kPa}$} & \multicolumn{2}{|c|}{$\begin{array}{c}W H P, 33-1500 \\
\mathrm{kPa}\end{array}$} & \multicolumn{2}{|c|}{$\begin{array}{c}F C P,>1500 \\
\mathrm{kPa}\end{array}$} & \multirow[b]{2}{*}{$\begin{array}{c}K c \\
\mathrm{~cm} \mathrm{~s}^{-1}\end{array}$} & \multirow[b]{2}{*}{$\frac{K_{S}}{K_{C}}$} \\
\hline & & $\begin{array}{c}K(\theta) \\
\mathrm{cm} \mathrm{s}^{-1}\end{array}$ & $\begin{array}{c}K(\theta) \\
\frac{K_{S}}{K_{C}}\end{array}$ & $\begin{array}{c}K(\theta) \\
\mathrm{cm} \mathrm{s}^{-1}\end{array}$ & $K$ & $\begin{array}{c}K(\theta) \\
\mathrm{cm} \mathrm{s}^{-1}\end{array}$ & $\mathrm{~K}(\theta)$ & $\begin{array}{c}\mathrm{K}(\theta) \\
\mathrm{cm} \mathrm{s}^{-1}\end{array}$ & $K(\theta)$ & & \\
\hline I & $0-30$ & $4.02^{-}$ & $3.46^{-4}$ & 1.69 & 15 & $6.88^{-4}$ & $5.92^{-5}$ & $1.67^{-7}$ & $1.44^{-8}$ & & 0.086 \\
\hline & $30-60$ & $5.37^{-}$ & $4.03^{-4}$ & $2.66^{-3}$ & & $6.28^{-4}$ & $4.71^{-5}$ & $1.40^{-7}$ & $1.05^{-8}$ & $3.66^{-2}$ & $0.0^{\prime}$ \\
\hline & 6 & 4.5 & $1.77^{-4}$ & $2.30^{-3}$ & $8.97^{-5}$ & $6.41^{-4}$ & $2.50^{-5}$ & $1.12^{-7}$ & $4.37^{-9}$ & & 0.039 \\
\hline III & $0-30$ & $4.75^{-3}$ & $8.07^{-5}$ & $2.81^{-3}$ & $4.78^{-5}$ & $7.05^{-4}$ & $1.20^{-5}$ & $1.20^{-7}$ & $2.04^{-9}$ & $6.06^{-2}$ & 0.017 \\
\hline Khat & $30-60$ & $4.19^{-3}$ & $7.54^{-5}$ & $2.56^{-3}$ & $4.61^{-5}$ & $8.54^{-4}$ & $1.54^{-5}$ & $1.12^{-7}$ & $2.02^{-9}$ & $3.88^{-2}$ & 0.018 \\
\hline & )-90 & 88 & $4.66^{-5}$ & 2.59 & $3.11^{-}$ & 7.93 & $9.52^{-6}$ & $6.90^{-8}$ & $8.28^{-10}$ & $5.40^{-2}$ & 0.012 \\
\hline
\end{tabular}

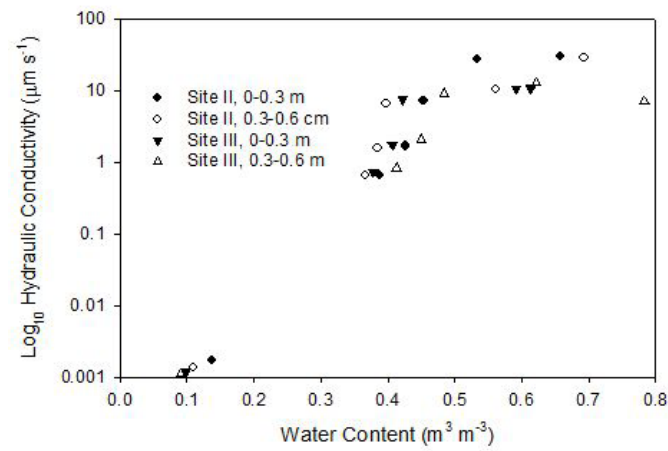

Figure 2. Mean values of calculated unsaturated hydraulic conductivity as a function of water content in the studied soil profiles (II, III)

As expected, the $K(\theta)$ values increased gradually from $W H P$ up to $R D P$. In the surface layer, the increase was from $5.93 \times 10^{-5}$ to $3.47 \times 10^{-4} \mathrm{~cm} \mathrm{~s}^{-1}$ for profile I and from $1.25 \times 10^{-5}$ to $8.45 \times 10^{-5} \mathrm{~cm} \mathrm{~s}^{-1}$ for profile III. In the subsurface layer, the increase was from $4.74 \times 10^{-5}$ to $6.10 \times 10^{-4} \mathrm{~cm} \mathrm{~s}^{-1}$ and from $1.52 \times 10^{-5}$ to $7.45 \times 10^{-5}$ for profile I and profile III respectively. Multiplying by the $C$ factor $\left(C=\frac{K_{S}}{K_{C}}\right)$ resulted in numerical values a couple orders of magnitude smaller, but the trends were similar.

\section{Comparison between the measured and predicted $K(\theta)$}

We will use the difference between the calculated results and the experimental data to determine accuracy of the prediction of $K(\theta)$. The root means square error (RMSE) was used to test the measured versus the predicted $K(\theta)$ as follows: 


$$
R M S E=\sqrt{\frac{\sum(K m-K p)^{2}}{n}}
$$

where: $m$ and $p$ refer to the measured and predicted $K(\theta)$, and $n$ is the number of the experimental data. Of course, the lowest value of $R M S E$ indicates the optimal value of the parameters that should be chosen.

The calculated $K(\theta)$ values compared quite well with the measured $K(\theta)$ values for the clay soil (Table 5) and sandy soil (Table 6). It was evident that the derived equations are applicable to a significant degree as the predicted and measured $K(\theta)$ values agree reasonably well for the clay soil and sandy soils.

Table 5. Measured $K(\theta)$ and calculated $K(\theta)$ for surface and subsurface depths of clay soil [IV]

\begin{tabular}{|c|c|c|c|c|c|c|c|c|}
\hline $\begin{array}{c}\text { Surface } \\
\text { depths }\end{array}$ & \multicolumn{4}{|c|}{$0-15 \mathrm{~cm}$} & \multicolumn{4}{|c|}{$15-30 \mathrm{~cm}$} \\
\hline Pore class & $\theta \%$ & $\begin{array}{c}\psi \\
\mathrm{kPa}\end{array}$ & $\begin{array}{c}\text { Measured } \\
K(\theta) \mathrm{cm} \mathrm{s}^{-1}\end{array}$ & $\begin{array}{l}\text { Calculated } \\
K(\theta) \mathrm{cm} \mathrm{s}^{-1}\end{array}$ & $\theta \%$ & $\begin{array}{c}\psi \\
\mathrm{kPa}\end{array}$ & $\begin{array}{c}\text { Measured } \\
K(\theta) \mathrm{cm} \mathrm{s}^{-1}\end{array}$ & $\begin{array}{l}\text { Calculated } \\
K(\theta) \mathrm{cm} \mathrm{s}^{-1}\end{array}$ \\
\hline$\overline{\mathrm{RDP}}$ & 42.1 & 9.6 & $1.49 * 10^{-5}$ & $6.29 * 10^{-5}$ & 42.3 & 7.6 & $2.81 * 10^{-5}$ & $1.00 * 10^{-4}$ \\
\hline \multirow{2}{*}{ SDP } & 38.5 & 19.6 & $6.07 * 10^{-6}$ & $1.38 * 10^{-5}$ & 40.3 & 16.4 & $1.13 * 10^{-5}$ & $2.06 * 10^{-5}$ \\
\hline & 34.2 & 30.8 & $3.12 * 10^{-6}$ & $4.96 * 10^{-6}$ & 36.2 & 25.2 & $5.90 * 10^{-6}$ & $7.85 * 10^{-6}$ \\
\hline \multirow{2}{*}{ WHP } & 33.3 & 35.4 & $2.08 * 10^{-6}$ & $3.66 * 10^{-6}$ & 35.5 & 30.0 & $3.99 * 10^{-6}$ & $5.43 * 10^{-6}$ \\
\hline & 32.5 & 39.5 & $1.56^{*} 10^{-6}$ & $2.87 * 10^{-6}$ & 33.2 & 34.0 & $2.95 * 10^{-6}$ & $3.95 * 10^{-6}$ \\
\hline $\begin{array}{c}\text { Subsurface } \\
\text { depths }\end{array}$ & \multicolumn{4}{|c|}{$30-45 \mathrm{~cm}$} & \multicolumn{4}{|c|}{$45-60 \mathrm{~cm}$} \\
\hline RDP & 42.8 & 6.4 & $3.59 * 10^{-5}$ & $1.44 * 10^{-4}$ & 42.9 & 6.0 & $4.20 * 10^{-5}$ & $1.64 * 10^{-4}$ \\
\hline SDP & 41.4 & 14.8 & $1.44 * 10^{-5}$ & $2.60 * 10^{-5}$ & 41.6 & 13.6 & $1.68 * 10^{-5}$ & $3.098 * 10^{-5}$ \\
\hline \multirow[t]{3}{*}{ SDP } & 40.1 & 21.2 & $7.64 * 10^{-6}$ & $9.28 * 10^{-6}$ & 40.7 & 23.4 & $8.85 * 10^{-6}$ & $1.07 * 10^{-5}$ \\
\hline & 39.0 & 28.8 & $5.03 * 10^{-6}$ & $6.47 * 10^{-6}$ & 39.5 & 26.8 & $5.90 * 10^{-6}$ & $7.57 * 10^{-6}$ \\
\hline & 36.8 & 32.0 & $3.65^{*} 10^{-6}$ & $4.95 * 10^{-6}$ & 38.8 & 31.0 & $4.25 * 10^{-6}$ & $5.56 * 10^{-6}$ \\
\hline
\end{tabular}

Table 6. Measured $K(\theta)$ and calculated $K(\theta)$ at a depth of $45 \mathrm{~cm}$ in sandy soil (V)

\begin{tabular}{|c|c|c|c|c|c|c|c|c|c|c|}
\hline $\begin{array}{l}\text { Pore } \\
\text { class }\end{array}$ & $\begin{array}{c}\text { Time, } \\
\mathrm{hr}\end{array}$ & $\begin{array}{c}\theta_{45} \\
\text { measured }\end{array}$ & $\begin{array}{c}\psi \\
\text { mbar }\end{array}$ & $d \theta / d t$ & $L d \theta / d t$ & $d H / d Z$ & $\begin{array}{c}\theta_{45} \\
\text { By Eq. }\end{array}$ & $\begin{array}{c}\text { Measured } \\
K(\theta) \\
\mathrm{cm} \mathrm{s}^{-1}\end{array}$ & $\begin{array}{c}\text { Calculated } \\
K(\theta) \mathrm{cm} / \mathrm{s} \\
(\text { Eq. } 7)\end{array}$ & $\left(K_{m}-K_{p}\right)^{2}$ \\
\hline \multirow[t]{10}{*}{$\overline{R D P}$} & 0.5 & 0.162 & 27 & -0.0756 & -3.6308 & -1 & 0.176 & $1.01 * 10^{-3}$ & $6.65 * 10^{-4}$ & $1.19 \times 10^{-7}$ \\
\hline & 2.0 & 0.121 & 43 & -0.0133 & -0.6377 & -0.8667 & 0.126 & $2.04 * 10^{-4}$ & $1.88 * 10^{-4}$ & $2.56 \times 10^{-10}$ \\
\hline & 2.5 & 0.097 & 45 & -0.0100 & -0.48195 & -0.906 & 0.107 & $1.47 * 10^{-4}$ & $1.46^{*} 10^{-4}$ & $1.00 \times 10^{-12}$ \\
\hline & 3.5 & 0.090 & 46 & -0.0066 & -0.3 & -0.8 & 0.094 & $1.10 * 10^{-4}$ & $1.22 * 10^{-4}$ & $1.44 \times 10^{-10}$ \\
\hline & 4.5 & 0.083 & 51 & -0.0048 & -0.2305 & -0.7667 & 0.091 & $8.35 * 10^{-5}$ & $9.64 * 10^{-5}$ & $1.66 \times 10^{-10}$ \\
\hline & 6.0 & 0.073 & 65 & -0.0033 & & -0.7333 & 0.078 & $6.09 * 10^{-5}$ & $5.09 * 10^{-5}$ & $1.00 \times 10^{-10}$ \\
\hline & 8.0 & 0.060 & 67 & -0 . & 99 & -0.7 & 0.068 & $4.44 * 10^{-5}$ & $4.18 * 10^{-5}$ & $6.76 \times 10^{-12}$ \\
\hline & 24.0 & 0.051 & 77 & -0.0006 & -0.0282 & -0.6667 & 0.057 & $1.18 * 10^{-5}$ & $2.64 * 10^{-5}$ & $10^{-10}$ \\
\hline & 48 & 0.045 & 85 & -0.0002 & -0 & -0.6338 & 0.052 & $5.17 * 10^{-6}$ & $1.98 * 10^{-5}$ & $2.14 \times 10^{-10}$ \\
\hline & 72.0 & 0.044 & 91 & -0.0001 & -0.0071 & -0.6 & 0.051 & $3.28 * 10^{-6}$ & $1.69 * 10^{-5}$ & $1.85 \times 10^{-10}$ \\
\hline \multirow[t]{3}{*}{ SDP } & 120 & 0.041 & 10 & -0.0 & & -0.4 & 0.046 & $2.58 * 10^{-6}$ & $1.24 * 10^{-5}$ & $9.64 \times 10^{-11}$ \\
\hline & 168 & 0.036 & 10 & -0.0 & -0.0025 & -0.4 & 0.038 & $1.67 * 10^{-6}$ & $9.68 * 10^{-6}$ & $6.41 \times 10^{-11}$ \\
\hline & 192 & 0.032 & 105 & -0.00004 & -0.0021 & -0.4 & 0.035 & $1.47 * 10^{-6}$ & $8.75 * 10^{-6}$ & $5.29 \times 10^{-11}$ \\
\hline
\end{tabular}

$\mathrm{Y}=\mathrm{at}^{\mathrm{m}}, \theta_{45}=0.1245 \mathrm{t}^{-0.2547,} d \theta / d t=-0.0317 \mathrm{t}^{-1.2547,}-L(d \theta / d t)=-1.4269 \mathrm{t}^{-1.2548}$

Sum $\left(K_{m}-K_{p}\right)^{2}=128.525919 \times 10^{-11}, \operatorname{Sum}\left(K_{m}-K_{p}\right)^{2} / 13=9.886609154 \mathrm{X} 10^{-11}$

The root means square error, $R M S E=9.9431 \times 10^{-6}$ 


\section{Statistical correlations between $K$ and $\theta$ for various pore size classes}

At FCP: $\mathrm{Y}=-1.29 \times 10^{-8}+5.896 \times 10^{-9} \mathrm{X}, \mathrm{r}=0.840^{* *}$

At $W H P: \mathrm{Y}=4.959 \times 10^{-7}+2.169 \times 10^{-5} \mathrm{X}, \mathrm{r}=0.999^{*}$

At $S D P: \mathrm{Y}=6.517 \times 10^{-4}+1.199 \times 10^{-4} \mathrm{X}, \mathrm{r}=0.813^{* *}$

At $R D P: \mathrm{Y}=4.253 \times 10^{-3}-7.321 \times 10^{-5} \mathrm{X}, \mathrm{r}=-0.575$

where: $\mathrm{Y}=K(\theta), \mathrm{X}=\theta$, and $\mathrm{r}$ is the correlation coefficient; * and ** means the confidence intervals for $\mathrm{Y}(=K(\theta)$ and $\mathrm{X}(=\theta)$ relations on $95 \%$ and $99 \%$ of correlation confidence respectively, [i.e. at the $5 \%$ level of significance (t05) and at the $1 \%$ level of significance $(\mathrm{t} 01)$ respectively]. $t$ is statistical test.

However, the point-based unsaturated hydraulic conductivity equations were useful for finely textured soils, and incorporated flow reduction in the dry soil due to adsorbed water, as well as enhanced flow through large pores at the wet location

\section{Water flow as related to soil pore sizes}

Water flow $(q)$ and $K$ through various pore classes could be specified for $F C P$ pores (in the dry location) and obtained in a cumulative way for all successive pores $(W H P, S D P, R D P)$ which still have water inside contribute to the conductivity values obtained. For example, $R D P$ includes the contribution of pore classes, which have a smaller size (i.e., $S D P, W H P, F C P$ ) to water flow and hydraulic conductivity. As water flow or (the drainage rate) $(q)$ may be calculated by Eq. 21, the water flux $(u)$, and how unsaturated water content varies with changes in the soil matric potential $(\Delta \psi)$ may be predicted by applying the classic Darcy's law;

$$
u=K(\theta) \frac{\Delta \psi}{\Delta L}
$$

Where, $u=\frac{q}{\pi r^{2}}$ i.e., the volume of water flowing through a unit cross-sectional area per unit time $t$. If the matric potential $(\Delta \psi)$ is acting over the distance of the moisture interval $(\Delta \mathrm{L})$ then a derivation may be made in terms of the total hydraulic head gradient $\frac{\Delta \psi}{\Delta L}$, equation (21) may then be applied to calculate the drainage rate $(q)$.

\section{CONCLUSION}

A theory was developed to determine the hydraulic conductivity $K(\theta)$ and simulate the soil water flow $(q)$ in the unsaturated state based on the soil water retention curve $\theta(h)$ and pore-size distribution. The data for the pore-size classes $(R D P, S D P$, $W H P, F C P$ ) were obtained for alluvial clay soilsfrom water retention curves as a percentage of the total volume of the pores and as a percentage of the total bulk volume of the studied soils. The values of $K(\theta)$ were calculated for each pore-size class by applying the assumed models. Each pore class includes the contribution of 
the pore classes which have a smaller size. The reduced influence of immobile adsorbed water $(\mathrm{Wa})$ on the water flow produces an advantage in the application of the approach to silt and clay soils which have considerable quantities of adsorbed water. There was a high significant correlation between $K$ and water content $(\theta)$ in capillary pore-size classes. The calculated $K(\theta)$ compared quite well with the measured $K(\theta)$ values for the clay soils. Finally, it should be emphasized that the proposed models are applicable in the calculation of unsaturated hydraulic conductivity $K(\theta)$ in coarse and finely textured soils, whereas many PTFS are more suited to sandy soils. Testing across a wider range of soil textures would be beneficial.

Conflict of interest: The Author does not declare conflict of interest.

\section{REFERENCES}

Amer A.M, Logsdon S.D., Davis D., 2009. Prediction of hydraulic conductivity in unsaturated soils. Soil Sci., 174(9), 508-515, https://doi.org/10.1097/SS.0b013e3181b76c29

Amer A.M., 1993. Surface area measurements as related to water vapor adsorption in arid soils of Egypt. Proc. Int. Conf. Desert Develop. 25-30 July, Mexico City, Mexico, 619-627.

Amer A.M., 1982. Effect of the overburden pressure on the capillary sorption potential of water in swelling soils. Ph.D. Thesis, Faculty of Soil Sci., Moscow State Univ., Moscow.

Amer A.M., 2001. Soil water movement and irrigation requirements (in Arabic). 1st Ed. El-Dar Al-Arabia for Publish., Cairo, Egypt, 438.

Amer A.M., 2002. Drainable and water-filled pores as related to water storage and conductivity in agricultural soils of the Nile Delta, SIL Proceedings, 1922-2010, 28, 4, 1912-1919, https://doi.org /10.1080/03680770.2001.11901962

Amer A.M., 2009. Moisture adsorption capacity and surface area as deduced from vapour pressure isotherms in relation to hygroscopic water of soils. Biologia, 64, 3, 516-521, https://doi.org/10.2478/ s11756-009-0073-z

Baver L.D., Gardner W.R., 1972. Soil physics. $4^{\text {th }}$ ed. John Wiley \& Sons, New York, 498.

Dane J.H., Topp G.C. (Eds), 2002. Methods of soil analysis, Part 4, Physical methods. SSSA, Madison, 1692.

El-Sharkawy A.F., 1994. Study of water imbibition in soil agricultural soils. M.Sc. Thesis, Faculty of Agriculture, Menoufia University, Shebin El-Kom, Egypt.

Hillel D., 1980. Fundamentals of soil physics. Academic Press, New York. 413, https://doi.org/10.1016/ B978-0-08-091870-9.50006-6

Khan G.S., Afzal T., 1989. Hydraulic characteristics of some important soil series of Pakistan. In: Soil physics in stress environments (Ed. M. Ahmed). Proceed. Inter. Sym. Soil physics in stress environments. 22-26 January. Islamabad, Pakistan, 222-237.

Khater E.A., 1978. Physical and micro-morphological studies in relation to soil moisture in alluvial soils of Egypt. Ph.D. Thesis, Fac. of Agric., Cairo Univ.

Klute A., 1972. The determination of hydraulic conductivity and diffusivity of unsaturated soil. Soil Sci., 113(4), 264-276, https://doi.org/10.1097/00010694-197204000-00006

Kosugi K., 1999. General model for unsaturated hydraulic conductivity for soils with lognormal pore-size distribution. Soil Sci. Soc. Am. J., 63, 270-277, https://doi.org/10.2136/sssaj1999. $03615995006300020003 x$ 
Marshall T.J., 1956. Relation between water and soil. Technical Communication No. 50, Commonwealth Bureau of Soils, Farenham Royal, Bucks, England.

Mualem Y., 1976. A new model predicting the hydraulic conductivity of unsaturated porous media. Water Res. Res., 12, 513-522, https://doi.org/10.1029/WR012i003p00513

Poulsen T.G., Moldrup P., Iversen B.V., Jacobsen O.H., 2002. Three-region Campbell model for unsaturated hydraulic conductivity in undisturbed soils. Soil Sci. Soc. Am. J., 66, 744-752, https://doi. org/10.2136/sssaj2002.7440

Schaap M.G., van Genuchten M.Th., 2006. A modified Mualen-van Genuchten formulation for improved description of the hydraulic conductivity near saturation. Vadose Zone J., 5, 27-34, https://doi.org/10.2136/vzj2005.0005

Sparks D.L. (Ed.), 1996. Methods of soil analysis, Part 3, Chemical methods. ASA, SSSA, Madison.

Stakman W.P., 1966. Determination of pore size by the air bubbly pressure method. Proceedings of UNESCO Symposium on Water in the Unsaturated Zone, 366-372.

Sudnitcyn E.E., 1979. Soil water movement and water requirements of crops. Moscow Univ. Ezdat, Moscow.

Vomocil J.A., 1965. "Porosity” in methods of soil analysis., Black. Agronomy Monograph, 9(I), 299314, Academic Press, New York. 